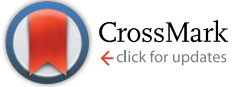

Cite this: RSC Adv., 2017, 7, 327
Received 21st October 2016 Accepted 30th November 2016 DOI: 10.1039/c6ra25630a

www.rsc.org/advances

\section{Novel $\pi$-conjugated iron oxide/reduced graphene oxide nanocomposites for high performance electrochemical supercapacitors $\dagger$}

\author{
Gourav Bhattacharya, ${ }^{a}$ Ganeshlenin Kandasamy, ${ }^{\mathrm{b}}$ Navneet Soin, ${ }^{\mathrm{c}}$ \\ Ravi Kant Upadhyay, ${ }^{a}$ Sujit Deshmukh, ${ }^{a}$ Dipak Maity, ${ }^{b}$ James McLaughlin ${ }^{d}$ \\ and Susanta Sinha Roy ${ }^{\star a}$
}

A novel nanocomposite consisting of $\pi$-conjugated 2 -aminoterephthalic acid (ATA) coated iron oxide $\left(\mathrm{Fe}_{3} \mathrm{O}_{4}\right)$ nanoparticles and reduced graphene oxide (RGO) has been synthesized using a facile combination of wet-chemistry and low-power sonication. The ATA- $\mathrm{Fe}_{3} \mathrm{O}_{4} / \mathrm{RGO}$ nanocomposites exhibited a high specific capacitance of the order of $576 \mathrm{~F} \mathrm{~g}^{-1}$; significantly higher than that of pristine $\mathrm{Fe}_{3} \mathrm{O}_{4}\left(132 \mathrm{~F} \mathrm{~g}^{-1}\right)$ and $\mathrm{RGO}\left(60 \mathrm{~F} \mathrm{~g}^{-1}\right)$ counterparts, indicative of a synergistic effect between the ATA- $\mathrm{Fe}_{3} \mathrm{O}_{4}$ and $\mathrm{RGO}$ components. Furthermore, the maximum energy storage density was calculated to be $75 \mathrm{~W} \mathrm{~h} \mathrm{~kg}^{-1}$ (at a current density of $6 \mathrm{~A} \mathrm{~g}^{-1}$ ). The charging-discharging analysis showed promising long-term stability with nearly $86 \%$ retention of the capacitance after 5000 cycles. The superior capacitive behaviour of these ATA- $\mathrm{Fe}_{3} \mathrm{O}_{4} / \mathrm{RGO}$ nanocomposites is attributed to the synergistic effect of the $\pi$-conjugated ATA coating on $\mathrm{Fe}_{3} \mathrm{O}_{4}$ which enhances the pseudo-capacitive charge transfer process of $\mathrm{Fe}_{3} \mathrm{O}_{4}$ and works in conjunction with the surface functional groups (such as carboxylic, amino and amide) present on the RGO surface, providing enhanced double layer capacitance. Thus, the current system exploits the advantages of both the double layer capacitors and pseudocapacitors in a hybrid structure.

\section{Introduction}

Recently, supercapacitors have garnered huge attention as portable power sources and power storage units. Furthermore, owing to their high energy density, long cycling life and capability to provide large power densities, they have been explored as starting power banks for renewable energy systems such as electrical vehicles and stationary fuel cells. ${ }^{1-6}$ The charge storage mechanism in supercapacitors mainly follows two routes: electrochemical double layer (EDLC) and pseudocapacitance..$^{7,8}$ The EDLCs work on the principal of electrostatic charge storage using reversible adsorption of electrolyte ions onto electrochemically stable high surface area carbon materials, while on the other hand the pseudocapacitors rely on the use of conducting polymers ${ }^{9}$ and transition metal oxides ${ }^{\mathbf{1 0}}$ to generate

${ }^{a}$ Department of Physics, School of Natural Sciences, Shiv Nadar University, Gautam Buddha Nagar 201314, Uttar Pradesh, India.E-mail: susanta.roy@snu.edu.in

${ }^{b}$ Nanomaterials Lab, Department of Mechanical Engineering, School of Engineering, Shiv Nadar University, Gautam Buddha Nagar 201314, Uttar Pradesh, India

'Institute for Materials Research and Innovation (IMRI), University of Bolton, Deane Road, Bolton, BL3 $5 A B$, UK

${ }^{d}$ Nanotechnology and Integrated Bioengineering Centre, University of Ulster, Jordanstown Campus, Newtownabbey, BT37 OQB, Northern Ireland, UK

$\dagger$ Electronic supplementary information (ESI) available. See DOI: 10.1039/c6ra25630a high capacitance via fast faradic reactions occurring at or near the solid electrode surface. In EDLCs, where the charge storage is non-faradic and electrostatic in nature, electrolyte ions are adsorbed onto the high surface area carbon-based materials such as carbon black, mesoporous carbon, carbon nanotubes (CNTs) ${ }^{11,12}$ and more recently graphene. ${ }^{13,14}$ Due to the charge separation at the electrode-electrolyte interface, the double layer capacitance is produced which is described by the classic Helmholtz capacitance leading to the formation of EDLC. ${ }^{15}$ In the case of EDLCs, high capacitance can be obtained by increasing the surface area and electrical conductivity of the material. ${ }^{5,16}$ The exotic properties of graphene such as extremely high surface area, chemical stability, high electrical conductivity and mechanical strength makes it a prospective and promising candidate for supercapacitor applications. ${ }^{\mathbf{1 7 , 1 8}}$ Moreover, the use of graphene as electrode material eliminates the need for separate current collector and where a current collector is still used, it reduces the contact resistance between current collector and electrodes owing to an additional advantage of low charge transfer resistance, thereby providing an additional benefit. ${ }^{19,20}$ The interest in pseudocapacitors arises from the higher value of capacitance and energy density obtained as compared to the EDLCs. ${ }^{21,22}$ While pseudocapacitors provide very high capacitance and power densities, however, their relatively low electrical conductivity and poor stability 
limit their usage. ${ }^{23}$ In order to increase their conductivity, they are often blended with other conductive carbon materials such as carbon black, CNTs and more recently, graphene. ${ }^{24}$ Graphene based nanocomposites have been used extensively in various electrochemical applications. ${ }^{25}$ Among the various transition metal oxides such as ruthenium oxide $\left(\mathrm{RuO}_{2}\right)$, manganese oxide $\left(\mathrm{MnO}_{2}\right),{ }^{26}$ nickel oxide $(\mathrm{NiO})$, copper oxide $(\mathrm{CuO})^{27}$ etc., iron oxide $\left(\mathrm{Fe}_{3} \mathrm{O}_{4}\right)$ is one of the most suitable and promising materials owing to its cost effectiveness and environmentally benign nature. ${ }^{28}$ In spite of its high pseudo-charge, the overall capacitance value is low because of its poor electrical conductivity thereby limiting the ion diffusion. ${ }^{29}$ It has been reported earlier that the mixing of conductive materials such as carbon nanotubes (CNT) and activated carbon etc. with $\mathrm{Fe}_{3} \mathrm{O}_{4}$ improves the overall capacitance of such systems significantly. ${ }^{30,31}$

Hybrid supercapacitors, utilizing both the faradic and non-faradic charge storage, potentially offer a solution to obtain high energy and power densities at the same time. Recently, graphene-metal oxide nanocomposites have been studied extensively as electrode materials, ${ }^{32,33}$ where the fast faradic reactions occurring on the metal oxide surface in conjunction with high conductivity of graphene tremendously improved the overall electrochemical performance of these nanocomposites. $^{34,35}$ Chemically functionalized graphene increases its effective electrochemical surface area by enhancing the number of sites where the electrolyte adsorption can take place. ${ }^{\mathbf{1 3} 36}$ Considering the above advantages, it is highly important to explore various graphene-metal oxide based advanced nanocomposites with enhanced electrochemical properties.

In this work, we have implemented an advanced strategy to enhance the capacitive performance of ATA- $\mathrm{Fe}_{3} \mathrm{O}_{4} / \mathrm{RGO}$ nanocomposites by increasing the double layer as well as pseudocapacitive behaviour, simultaneously. The carboxylic $(-\mathrm{COOH})$ and amino $\left(-\mathrm{NH}_{2}\right)$ groups of 2-aminoterephthalic acid coated iron oxide nanoparticles interact synergistically with the residual functional groups on the partially reduced graphene oxide to exhibit supercapacitive behaviour as analysed by cyclic voltammetry, electrochemical impedance and galvanostatic charging-discharging measurements.

\section{Materials and methods}

\subsection{Materials}

Ferrous chloride $\left[\mathrm{Fe}(\mathrm{Cl})_{2} \cdot 4 \mathrm{H}_{2} \mathrm{O}\right]$, ferric chloride $\left[\mathrm{Fe}(\mathrm{Cl})_{3} \cdot 6 \mathrm{H}_{2} \mathrm{O}\right]$, 2-aminoterephthalic acid (ATA), ammonium hydroxide $\left(\mathrm{NH}_{4} \mathrm{OH}\right)$ and potassium hydroxide $(\mathrm{KOH})$ were purchased from Fisher Scientific. Graphene oxide (GO) was purchased from Sigma Aldrich. All the aqueous solutions were prepared with ultrapure water (Millipore-Q systems: measured electrical resistivity $\sim 18 \mathrm{M} \Omega \mathrm{cm}$ at room temperature $(298 \mathrm{~K})$ ).

\subsection{Synthesis}

2.2.1. Synthesis of reduced graphene oxide (RGO). A $20 \mathrm{ml}$ aqueous dispersion of GO $\left(0.25 \mathrm{mg} \mathrm{ml}^{-1}\right)$ was prepared by magnetic stirring at $500 \mathrm{rpm}$ at $70{ }^{\circ} \mathrm{C}$ for 6 hours. To synthesize
RGO, $3 \mathrm{ml}$ of $\mathrm{NH}_{4} \mathrm{OH}$ was added drop wise to the aqueous solution of GO and left to stir overnight after which the colour of the solution became black. The RGO solution was then centrifuged at $5000 \mathrm{rpm}$ to exclude large clusters and washed repeatedly with water and ethanol to eliminate any traces of residual ammonia. Finally, the wet RGO sample was dried at $60{ }^{\circ} \mathrm{C}$ to obtain RGO powders which were then subsequently used to prepare ATA- $\mathrm{Fe}_{3} \mathrm{O}_{4} / \mathrm{RGO}$ nanocomposites. The confirmation of reduction process was carried out using Raman spectroscopy (Fig. S3, ESI $\dagger$ ) as well as X-ray diffraction analysis (see Fig. S2 inset, ESI $\dagger$ ).

2.2.2. Synthesis of $\pi$-conjugated $\mathrm{ATA}-\mathrm{Fe}_{3} \mathrm{O}_{4}$ nanoparticles and $\mathrm{ATA}-\mathrm{Fe}_{3} \mathrm{O}_{4} / \mathbf{R G O}$ nanocomposites. Iron oxide nanoparticles were synthesized via a chemical-co-precipitation method using ATA as the capping agent. $1.17 \mathrm{~g}$ of $\mathrm{FeCl}_{3} \cdot 6 \mathrm{H}_{2} \mathrm{O}, 0.43 \mathrm{~g}$ of $\mathrm{FeCl}_{2} \cdot 4 \mathrm{H}_{2} \mathrm{O}$ and $0.82 \mathrm{~g}$ of ATA were added together to a $150 \mathrm{ml}$ round bottom flask containing $22.5 \mathrm{ml}$ of distilled water. The reaction mixture was magnetically stirred and heated to $80{ }^{\circ} \mathrm{C}$ for 60 minutes under constant $\mathrm{N}_{2}$ gas flow. Then $2.5 \mathrm{ml}$ of $25 \%$ $\mathrm{NH}_{4} \mathrm{OH}$ (in $\mathrm{H}_{2} \mathrm{O}$ ) was rapidly added to the reaction mixture to initiate the nucleation of iron oxide nanoparticles. The resultant reaction mixture whose $\mathrm{pH}$ was maintained between 10 and 11 , was vigorously stirred for next 60 minutes at $80^{\circ} \mathrm{C}$ and then cooled down to room temperature afterwards. The resultant nanoparticles were magnetically separated and washed with ethanol and distilled water. The molar ratio during the synthesis ATA- $\mathrm{Fe}_{3} \mathrm{O}_{4}$ was kept at ATA: $\mathrm{Fe}_{3} \mathrm{O}_{4}=1: 3$, the complete procedure has been reported previously in the literature. ${ }^{37}$ In order to investigate the role of amount of ATA on the electrochemical performance, the molar ratio was further varied to ATA : $\mathrm{Fe}_{3} \mathrm{O}_{4}=2: 3$ and ATA : $\mathrm{Fe}_{3} \mathrm{O}_{4}=1: 6$. The samples were marked as ATA- $1 \mathrm{M}(1: 3)$, ATA- $2 \mathrm{M}(2: 3)$ and ATA-0.5 $\mathrm{M}(1: 6)$. The ATA coated iron oxide nanoparticles were then used for the preparation of nanocomposites with reduced graphene oxide. Uniform aqueous dispersions of partially reduced graphene oxide and $\mathrm{ATA}-\mathrm{Fe}_{3} \mathrm{O}_{4}$ at various concentrations were prepared. Four weight ratios of iron oxide/RGO $\left(\right.$ ATA- $\mathrm{Fe}_{3} \mathrm{O}_{4}: \mathrm{RGO}=1: 2$, $1: 1,2.5: 1,5: 1)$ nanocomposites, having different concentrations in aqueous solutions $\left(0.1 \mathrm{mg} \mathrm{ml}^{-1}, 0.5 \mathrm{mg} \mathrm{ml}^{-1}, 1 \mathrm{mg}\right.$ $\mathrm{ml}^{-1}, 2 \mathrm{mg} \mathrm{ml}{ }^{-1}$ ) were then added and ultrasonicated in a low power $(50 \mathrm{~W})$ bath sonicator at room temperature for 30 minutes to obtain nanocomposites. Low power sonication method has been reported earlier in the literature ${ }^{38}$ to produce RGO based nanocomposites.

\subsection{Experimental}

2.3.1. Morphology analysis. To examine the morphology of the samples, the TEM and high resolution TEM (HRTEM) images were taken using a Field-emission gun transmission electron microscopy (FEG-TEM) (Tecnai G2, F30, FEI). Scanning electron microscopy images were recorded using a scanning electron microscope (Zeiss EVO40). Fourier transformed infrared (FTIR) spectra were collected on a Thermo Fisher Scientific instrument between 4000 to $650 \mathrm{~cm}^{-1}$ at ambient condition, with a resolution of $\pm 4 \mathrm{~cm}^{-1}$ utilizing the transmission mode. The spectra were analyzed using vendor 
provided Thermo Insight software. The absorbance was collected using UV-Vis-NIR spectrophotometer (Shimadzu, Solidspec 3700) in the wavelength range of 200-900 nm utilizing a unpolarized light. The X-ray diffraction (XRD) analysis was performed using Bruker D8-Discover with $\mathrm{Cu}-\mathrm{K} \alpha$ radiation $(\lambda=$ $0.154 \mathrm{~nm}$ ). The Raman measurements were carried out using STR Micro Raman Spectrometer (Model STR 500) with $532 \mathrm{~nm}$ laser source.

2.3.2. Electrochemical measurement. The cyclic voltammetry (CV), galvanostatic charge-discharge and electrochemical impedance spectroscopy measurements were performed on an Autolab Potentiostat Galvanostat PGSTAT302N (Metrhom, Netherlands). For the CV measurements, a three electrode set up consisting of $\mathrm{Ag} / \mathrm{AgCl}$ as the reference electrode, platinum wire as the counter electrode and glassy carbon electrode (GCE) with drop-dried ATA- $\mathrm{Fe}_{3} \mathrm{O}_{4} / \mathrm{RGO}$ as the working electrode, was utilized. The CV scans were carried out between $-0.4 \mathrm{~V}$ to $0.8 \mathrm{~V}$ using $1 \mathrm{M} \mathrm{KOH}$ as the supporting electrolyte. ${ }^{39}$ The galvanostatic charge-discharge measurements were carried out in the chrono-potentiometery mode with a similar 3 electrode set up as used in the CV measurements. The cut-off voltages set during these measurements were obtained from the CV measurements. The impedance measurements were carried out in the FRA potential scan mode with a two-electrode set up. A $5 \mathrm{~mm}$ diameter GCE coated with the ATA- $\mathrm{Fe}_{3} \mathrm{O}_{4} / \mathrm{RGO}$ active material was used as the working electrode along with platinum wire as the counter electrode. The EIS measurements were carried out at room temperature in $1 \mathrm{M} \mathrm{KOH}$. For measurements, a sinusoidal alternating current (a.c) perturbation voltage with root mean square (r.m.s) value of $10 \mathrm{mV}$ was applied while the frequency was varied from 0.1 to $100 \mathrm{kHz}$. The spectrum was fitted using NOVA software.

\section{Results and discussions}

\subsection{Morphology analysis}

For direct morphological visualization, SEM images were taken for ATA- $\mathrm{Fe}_{3} \mathrm{O}_{4} / \mathrm{RGO}$ nanocomposites and is represented in the Fig. S1 (ESI $\dagger$ ), wherein the figures show the decoration of iron oxide nanoparticles on RGO flakes. TEM analysis was carried out to analyse the morphology and microstructural properties of the pristine components and the ATA- $\mathrm{Fe}_{3} \mathrm{O}_{4} / \mathrm{RGO}$ nanocomposites. The TEM images of nanocomposite samples are shown in Fig. 1. It can be clearly seen from the image (Fig. 1a) that the sample consists of spherical ATA- $\mathrm{Fe}_{3} \mathrm{O}_{4}$ nanoparticles, with a size range of $4-10 \mathrm{~nm}$. The selected area electron diffraction (SAED) pattern further confirms high crystallinity of the sample (Fig. 1b). The TEM image (Fig. 1d and e) of the ATA- $\mathrm{Fe}_{3} \mathrm{O}_{4} / \mathrm{RGO}$ nanocomposites at a weight ratio of $1: 1$ clearly shows the attachment of ATA- $\mathrm{Fe}_{3} \mathrm{O}_{4}$ onto the RGO sheet surface.

To further investigate the crystal structure of the nanocomposites, XRD analysis was performed (Fig. S2, ESI $\dagger$ ). XRD peaks were found to be in close proximity with the standard peaks for inverse spinel phase of $\mathrm{Fe}_{3} \mathrm{O}_{4}$ (JCPDS card no. 19-0629). The broad hump between the $2 \theta$ values of $20-30^{\circ}$ correspond to the relatively short range ordering of RGO (inset of Fig. S2 $\dagger$ ). This hump is also present in the XRD pattern of the ATA- $\mathrm{Fe}_{3} \mathrm{O}_{4}-\mathrm{RGO}$ nanocomposites. For GO, the diffraction peak appearing around $10.7^{\circ}$ (inset Fig. $\mathrm{S} 2 \dagger$ ) became broader and less prominent for the case of RGO. From XRD spectra, the $d$ spacing of GO was found to be $0.825 \mathrm{~nm}$. This high $d$-spacing indicates the intercalation of water molecules as well as the formation of oxygen containing functional groups in between graphitic layers. For RGO samples, the low angle broad peak indicates the residual oxygen containing functional groups still present in RGO. The inter-planer spacing of RGO was also evaluated to be $0.378 \mathrm{~nm}$ (from the higher angle peak of RGO), thereby confirming the reduction of GO to RGO.

Reduction of GO to RGO was also monitored and confirmed using Raman spectroscopy (Fig. S3, ESI $\dagger$ ). The intensity ratio of the $\mathrm{D}$ to the $\mathrm{G}$ band $\left(I_{\mathrm{D}} / I_{\mathrm{G}}\right)$ for $\mathrm{GO}$ was found to be 0.911 , which increased to 1.04 in the case of RGO. This increase in the $I_{\mathrm{D}} / I_{\mathrm{G}}$ ratio for RGO suggests that the reduction process has altered the structure of GO with more structural defects. ${ }^{\mathbf{4 0 , 4 1}}$ This was accompanied by the movement of the $\mathrm{G}$ band to lower peak position (1588 $\mathrm{cm}^{-1}$ for RGO) as compared to GO $\left(1592 \mathrm{~cm}^{-1}\right)$ with a reduction in the FWHM as well (from $62 \mathrm{~cm}^{-1}$ to 54 $\mathrm{cm}^{-1}$ ), further confirming the reduction of GO. This change in the peak position, suggests a decrease in the average size of the $\mathrm{sp}^{2}$ domains upon reduction of the $\mathrm{GO},{ }^{42}$ whereas the decrease in the FWHM indicates enhanced $\mathrm{sp}^{2}$ carbon atoms. ${ }^{43}$ Apart from the increase in the $I_{\mathrm{D}} / I_{\mathrm{G}}$ ratio, a comparatively more prominent $2 \mathrm{D}$ peak in the Raman spectrum of RGO was also observed.

The possible mode of attachment of the ATA- $\mathrm{Fe}_{3} \mathrm{O}_{4}$ on the RGO sheet is described by the schematic shown in Fig. 2. There are mainly three possible ways of attachments: (i) attachment of $-\mathrm{NH}_{2}$ (amino) group of ATA with $-\mathrm{COOH}$ (carboxylic) group of RGO to form -CONH (amide) linkage; (ii) physical adsorption of nanoparticles over RGO and (iii) attachment of nanoparticles at the defect sites of the RGO. The presence of amino and carboxylic groups on the surface of nanocomposites is confirmed by FTIR analysis $\left(1470 \mathrm{~cm}^{-1}\right.$ (-NH bending), 1725 $\mathrm{cm}^{-1}\left(\mathrm{C}=\mathrm{O}\right.$ stretching) and $3210 \mathrm{~cm}^{-1}(\mathrm{O}-\mathrm{H}$ stretching $\left.)\right)$ (Fig. S4, ESI $\dagger$ ). The study also reveals the $-\mathrm{CONH}$ linkage between the particles $\left(1570 \mathrm{~cm}^{-1}\right)$ which is in accordance to our proposed interaction scheme (marked 1 in Fig. 2). From the inset of Fig. S4 (ESI $\dagger$ ), it is quite evident that the peak corresponds to hydroxyl group for RGO decreases significantly than that of GO $\left(3210 \mathrm{~cm}^{-1}\right)$. Also, previously proposed mechanism for the reduction of GO to RGO suggested that the hydride transfer to epoxide is one of the key step in the reduction process. From the figure, it is also evident that the area under the curve for the epoxide region $870-1170 \mathrm{~cm}^{-1}$ decreased significantly in case of RGO implying the reduction of GO.

To further investigate the attachment of ATA on $\mathrm{Fe}_{3} \mathrm{O}_{4}$ and the interaction between $\mathrm{ATA}-\mathrm{Fe}_{3} \mathrm{O}_{4}$ and $\mathrm{RGO}$, UV-Visible spectra was recorded in absorbance mode in the wavelength range of 200-900 $\mathrm{nm}$ (Fig. S5, ESI $\dagger$ ). The uncoated $\mathrm{Fe}_{3} \mathrm{O}_{4}$ does not exhibit any considerable strong absorption peaks and matches with the literature. ATA samples show two characteristic peaks around $\sim 355 \mathrm{~nm}$ and $\sim 245 \mathrm{~nm}$. The strong absorption around $\sim 355 \mathrm{~nm}$ is attributed to the $\pi-\pi^{*}$ transition 


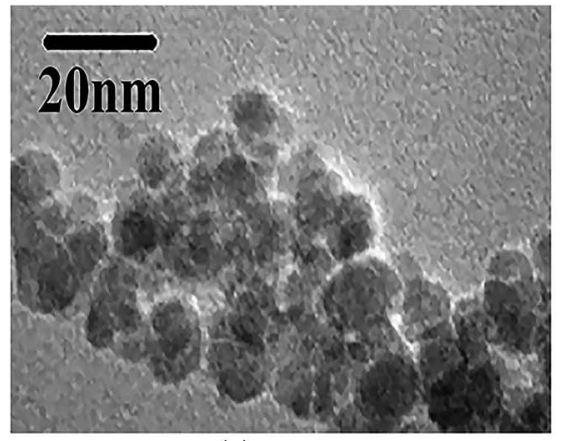

(a)

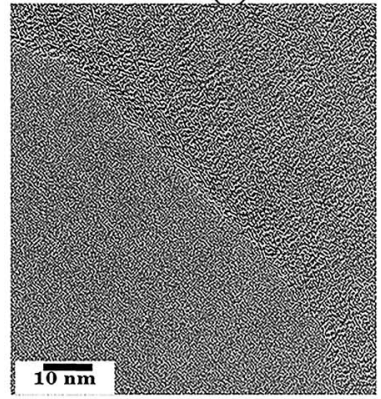

(c)

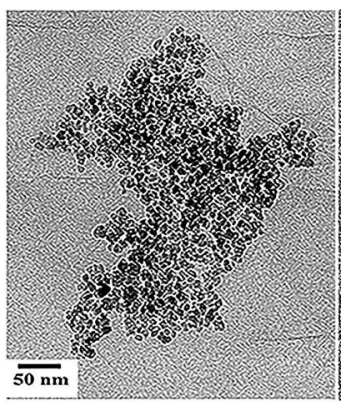

(d)

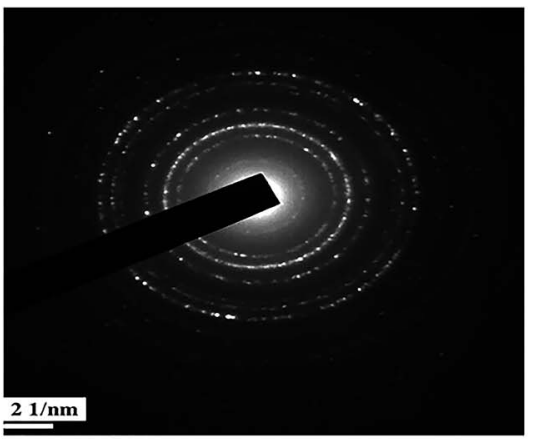

(b)

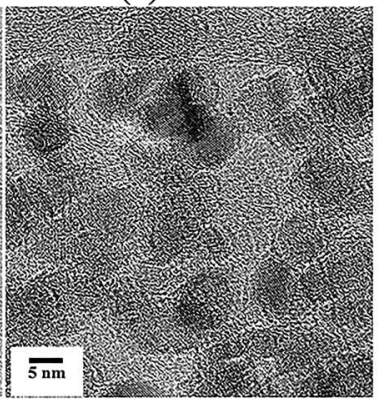

(e)

Fig. 1 (a and c) correspond to TEM images of ATA coated iron oxide and RGO ((b) represents the SAED pattern of Fe $\mathrm{O}_{4}$ ). ( $d$ and e) correspond to TEM images of $\mathrm{ATA}-\mathrm{Fe}_{3} \mathrm{O}_{4} / \mathrm{RGO}$ nanocomposite of weight ratio $A T A-\mathrm{Fe}_{3} \mathrm{O}_{4}: \mathrm{RGO}=1: 1$ at different resolutions.

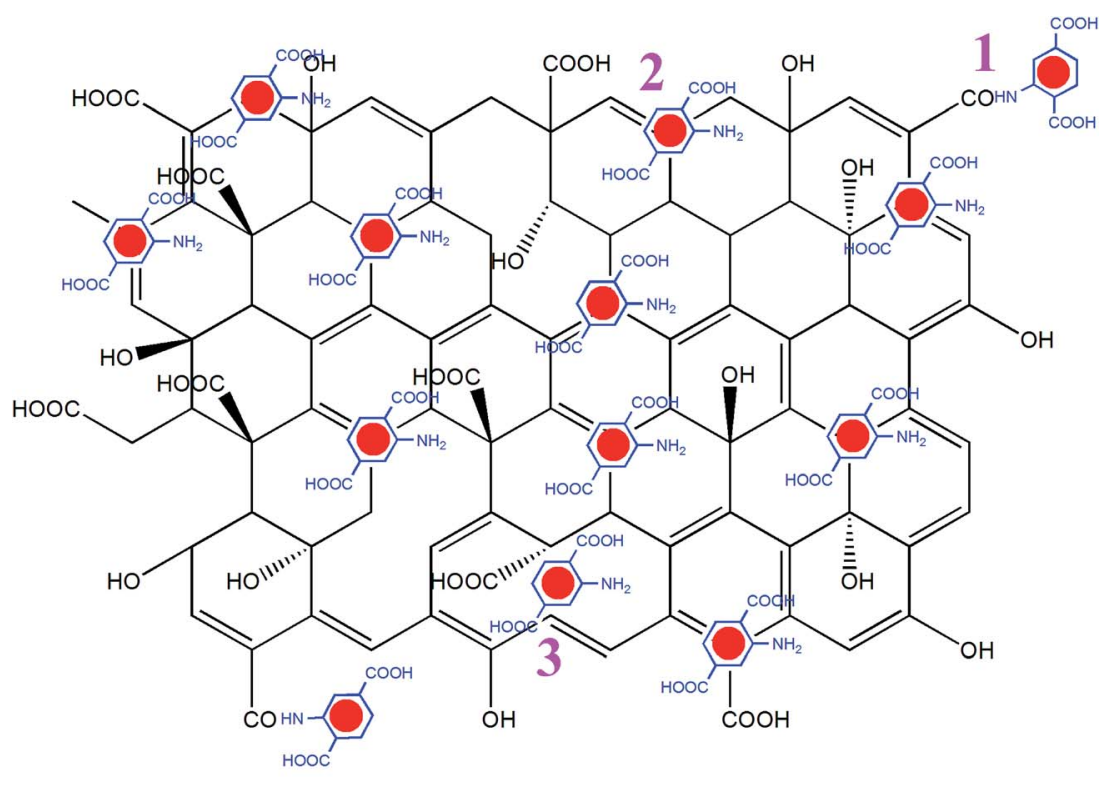

ATA Coated $\mathrm{Fe}_{3} \mathrm{O}_{4}$

Fig. 2 Three distinct possibilities of attachment of ATA coated iron oxide nanoparticles over RGO are shown in the schematic.

of lone pair of amino group. ${ }^{44}$ Whereas the ATA coated sample clearly displays two sharp peaks at $330 \mathrm{~nm}$ and $220 \mathrm{~nm}$ which are in agreement with the reported values. ${ }^{45}$ The blue shift in case of the coated sample could be ascribed as the perturbation by the metallic centre ${ }^{46,47}$ of $\mathrm{Fe}_{3} \mathrm{O}_{4}$. In case of ATA-Fe $\mathrm{O}_{4}: \mathrm{RGO}$ nanocomposite sample, the peaks become sharper indicating a strong attachment. 


\subsection{Electrochemical analysis}

3.2.1. Cyclic voltammetry (CV). Detailed CV studies were carried out to optimize the weight ratio of nanoparticles and RGO in order to achieve the maximum supercapacitor behaviour. It was observed that $1: 1$ loading at a concentration of $1 \mathrm{mg} \mathrm{ml}^{-1}$ of ATA- $\mathrm{Fe}_{3} \mathrm{O}_{4}$ and RGO shows the highest specific capacitance value at a scan rate $50 \mathrm{mV} \mathrm{s}^{-1}$ (Fig. S6 and Table S1, ESI $\dagger$ ). It has previously been reported that at higher loadings, the agglomeration and formation of clusters of $\mathrm{Fe}_{3} \mathrm{O}_{4}$ nanoparticles leads to a lower electrochemical surface area thereby leading to a reduction in the specific capacitance of the samples. ${ }^{48}$ The CV scans (Fig. 3a) carried out for incremental scan rates of $10-100 \mathrm{mV} \mathrm{s}^{-1}$ for the $1: 1$ ratio of $\mathrm{ATA}-\mathrm{Fe}_{3} \mathrm{O}_{4}$ : RGO nanocomposite between -0.4 to $0.8 \mathrm{~V}$ look relatively featureless and exhibit a nearly rectangular shape, representative of the supercapacitor behaviour. ${ }^{49}$ A small peak corresponding to the $\mathrm{Fe}(\mathrm{III})-\mathrm{Fe}(\mathrm{II})$ transition is observed at around $-0.1 \mathrm{~V}$ (Fig. S7, ESI $\dagger$ ). It is to be mentioned that for uncoated iron oxide the corresponding peak lies in more negative voltage $(\leq-0.25 \mathrm{~V})$ and is reported in literature..$^{33}$ In the present study, the CV of uncoated and ATA coated iron oxide is plotted in Fig. S8 (ESI $\dagger$ ) wherein the shift in the reduction peak can be attributed to the ATA attachment. This quasi-rectangular shape of the CV curve is suggestive of the ideal double layer capacitance with fast charge transport. ${ }^{50}$ In fact, the currents obtained for the ATA- $\mathrm{Fe}_{3} \mathrm{O}_{4} / \mathrm{RGO}$ composites are significantly higher than that of pristine $\mathrm{ATA}-\mathrm{Fe}_{3} \mathrm{O}_{4}$ and pristine RGO samples, indicating enhanced electrochemical charge storage capabilities of the nanocomposites. The specific-capacitance is calculated from the cyclic voltammetry curve using the following equation:

$$
C_{\mathrm{s}}=0.5 \times \oint[\mathrm{d} i /\{(\mathrm{d} V / \mathrm{d} t) / m\}]
$$

where $C_{\mathrm{s}}$ is the specific capacitance, $\mathrm{d} V / \mathrm{d} t$ represents the scan rate and $m$ is the active mass of the material on the GCE. The factor 0.5 is multiplied to get either cathodic or anodic current.
Once it had been established that the $1: 1$ loading of ATA$\mathrm{Fe}_{3} \mathrm{O}_{4}$ and RGO shows the highest specific capacitance, the concentration of the nanocomposites (ATA- $\mathrm{Fe}_{3} \mathrm{O}_{4}: \mathrm{RGO}=$ $1: 1)$ in aqueous solution was varied, wherein the maximum capacitance is observed at a concentration of $1 \mathrm{mg} \mathrm{ml}^{-1}$ (Fig. S7, ESI $\dagger$ ). The specific capacitance of the nanocomposites as a function of scan rate is plotted in Fig. $3 \mathrm{~b}$, wherein at the lowest scan rate of $10 \mathrm{mV} \mathrm{s}^{-1}$ the capacitance of $\mathrm{ATA}-\mathrm{Fe}_{3} \mathrm{O}_{4} / \mathrm{RGO}$ nanocomposites is found to be $576 \mathrm{~F} \mathrm{~g}^{-1}\left(132 \mathrm{~F} \mathrm{~g}^{-1}\right.$ and $60 \mathrm{~F} \mathrm{~g}^{-1}$ for pristine ATA coated $\mathrm{Fe}_{3} \mathrm{O}_{4}$ and partially reduced graphene oxide, respectively at the same scan rates). It is important to mention that at the scan rate of $50 \mathrm{mV} \mathrm{s}^{-1}$, the capacitance for pristine ATA coated $\mathrm{Fe}_{3} \mathrm{O}_{4}$ and partially reduced graphene oxide is found to be $30 \mathrm{~F} \mathrm{~g}^{-1}$ and $17 \mathrm{~F} \mathrm{~g}^{-1}$, respectively. Thus, the significant increase in capacitance value of the composites $(245$ $\mathrm{F} \mathrm{g}^{-1}$ at scan rate $50 \mathrm{mV} \mathrm{s}^{-1}$ ) can be credited to the synergistic effect of both the materials. ${ }^{51}$ The $\pi$-conjugation path favours the effectual spin-transfer from the metallic core of iron oxides to the external surfaces that are in contact with the bulk, for instance, the surrounding electrolyte environment. Thus, the $\pi$ conjugation of ATA coating with $\mathrm{Fe}_{3} \mathrm{O}_{4}$ nanoparticles enhances the fast charge transfer kinetics and consequently the faradic capacitance $^{52}$ of the nanocomposite system. The specific amount of ATA would provide the uniform coating of $\mathrm{Fe}_{3} \mathrm{O}_{4}$. The amount of ATA is important to form an optimal colloidal suspension which would lead to minimal agglomeration of $\mathrm{Fe}_{3} \mathrm{O}_{4}$ nanoparticles. To study the effect of mass of ATA on capacitance performance cyclic voltammetry analysis was carried by varying the molar ratio between ATA and $\mathrm{Fe}_{3} \mathrm{O}_{4}$ (Fig. S9, ESI $\dagger$ ). From the figure, it is clear that the ATA-1 M sample exhibit the highest specific capacitance amongst all the samples as at this molar ratio, the $\mathrm{Fe}_{3} \mathrm{O}_{4}$ nanoparticles are uniformly coated with least agglomeration. Due to the optimal coating, the ATA- $\mathrm{Fe}_{3} \mathrm{O}_{4}$ samples present the highest surface area and enhanced wettability leading to enhanced electrochemical performance.
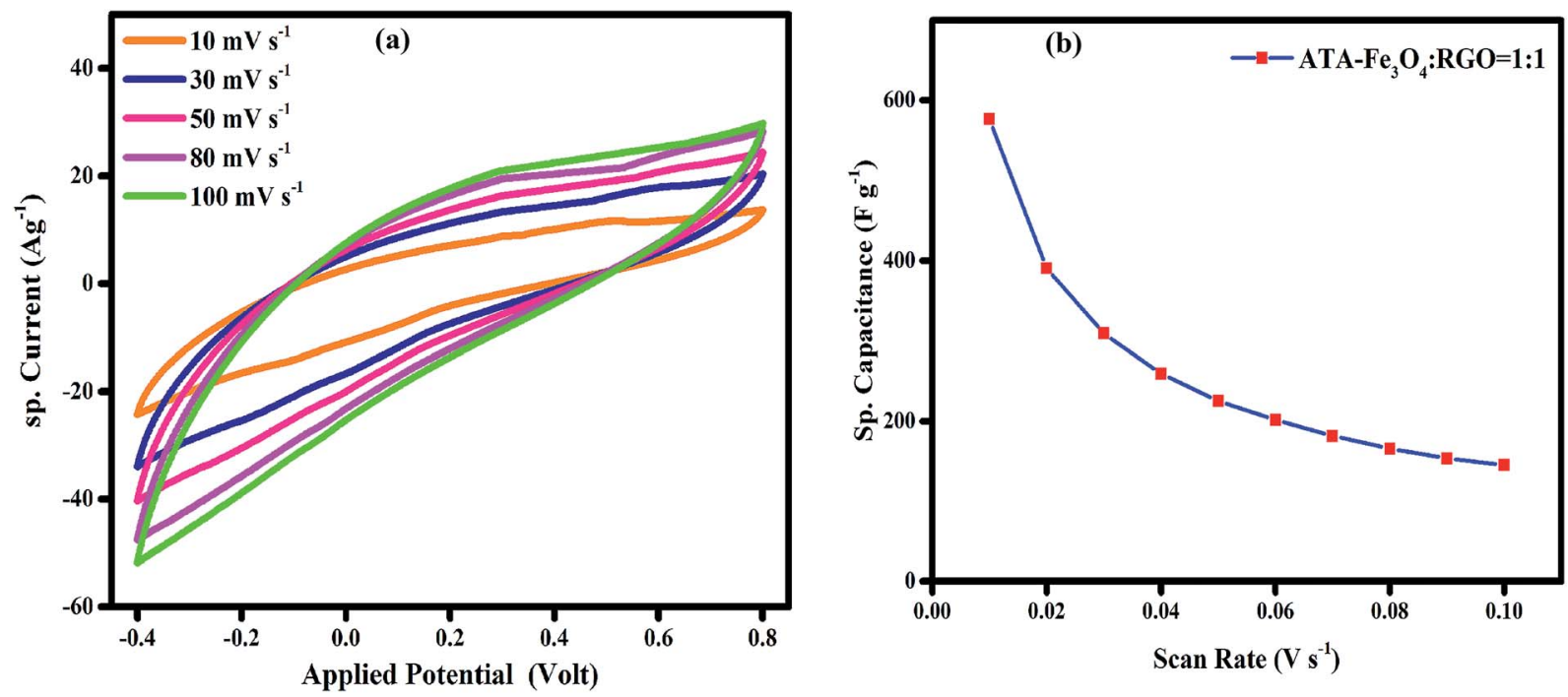

Fig. 3 (a) Cyclic voltammogram of $\mathrm{ATA}-\mathrm{Fe}_{3} \mathrm{O}_{4} / \mathrm{RGO}$ nanocomposite (ATA-Fe $\mathrm{O}_{4}: \mathrm{RGO}=1: 1$ ) in $1 \mathrm{M}$ aqueous $\mathrm{KOH}$ solution. (b) is the variation of specific capacitance with scan rate for $\mathrm{ATA}-\mathrm{Fe}_{3} \mathrm{O}_{4} / \mathrm{RGO}$ nanocomposite $\left(\mathrm{ATA}-\mathrm{Fe}_{3} \mathrm{O}_{4}: \mathrm{RGO}=1: 1\right.$ ) in $1 \mathrm{M}$ aqueous $\mathrm{KOH}$ solution. 
3.2.2. Galvanostatic charge discharge. The specific capacitance values were also calculated from the galvanostatic charge discharge analysis by employing the following equation:

$$
C_{\mathrm{s}}=-[i /\{(\mathrm{d} V / \mathrm{d} t) \times m\}]
$$

where $C_{\mathrm{s}}$ is the specific capacitance, $m$ is the effective mass and $\mathrm{d} V / \mathrm{d} t$ is the average slope of the discharge cycle. The near symmetric charge-discharge cycles (Fig. 4a) are representative of the good capacitive behaviour of the composite materials, ${ }^{53}$ while the curvature in the discharge cycle indicates the presence of pseudocapacitance ${ }^{54}$ which can be attributed to the presence of $\mathrm{Fe}_{3} \mathrm{O}_{4}$ nanoparticles. Also, the charge-discharge duration of the nanocomposites is much higher than that of the individual RGO and $\mathrm{Fe}_{3} \mathrm{O}_{4}$ components indicating a higher specific capacitance value, ${ }^{32}$ consistent with the corresponding $\mathrm{CV}$ measurements. The specific capacitance value of $375 \mathrm{~F} \mathrm{~g}^{-1}$ at a specific current of $6 \mathrm{~A} \mathrm{~g}^{-1}$ was calculated for the nanocomposites. The areal capacitance, also calculated from the charge discharge curve (Fig. S10, ESI $\dagger$ ) is found to be $0.68 \mathrm{~F}$ $\mathrm{cm}^{-2}$ at a specific current of $5 \mathrm{~mA} \mathrm{~cm}{ }^{-2}$. The variation of the specific capacitance as a function of specific current is also plotted and represented in Fig. S11 (ESI $\dagger$ ) and shows the typical behaviour, wherein the specific capacitance decreases with an increase in the specific current density. It is pertinent to mention here that the higher effective surface area makes it more favourable for the electrolyte to wet the surface thereby increasing the effective double layer length and consequently the capacitance. In our case, functionalized $\mathrm{Fe}_{3} \mathrm{O}_{4}$ and RGO serves the purpose of enhancing the surface area and consequently the capacitance. ${ }^{39,55}$ Partially reduced graphene oxide contains many defects and also carboxylic groups apart from the other oxygen containing groups. These defect sites provide more accessible area for the attachment of ATA coated iron oxide with $\mathrm{RGO}^{56,57}$ and the carboxylic groups of RGO may interact with the amino groups of ATA molecule to form amide linkage. The main problem in pseudocapacitance is high diffusion resistance which hinders the ion transport process. ${ }^{58}$ In our case this problem is mitigated in two ways: (i) by introducing defect induced RGO and (ii) the $\pi$ conjugated ATA coating. These two factors provide enhanced charge transfer kinetics which further enhance the ion transport ${ }^{59,60}$ and thereby increasing the specific capacitance values.

To probe the long-term stability and durability, we performed charging discharging analysis for an extensive number of cycles and the variation of specific capacitance with each cycle is plotted in Fig. 4 b. The result shows that nearly $86 \%$ of the starting capacitance values are retained even after 5000 cycles. It has been reported earlier that the agglomeration of the metal oxide nanoparticles during the electrochemical charging is the root cause of the decline in cyclic performance. ${ }^{48}$ In the literature, it has been reported that the presence of graphene provides a favourable surface for the adsorption of nanoparticles which avoids their agglomeration. ${ }^{61}$ However, in our study it is revealed that in spite of presence of RGO, the uncoated $\mathrm{Fe}_{3} \mathrm{O}_{4}$ nanocomposite shows relatively low capacitance value, thus indicating that the surface functional groups and coating on the $\mathrm{Fe}_{3} \mathrm{O}_{4}$ nanoparticles play a key role in prevention of agglomeration.

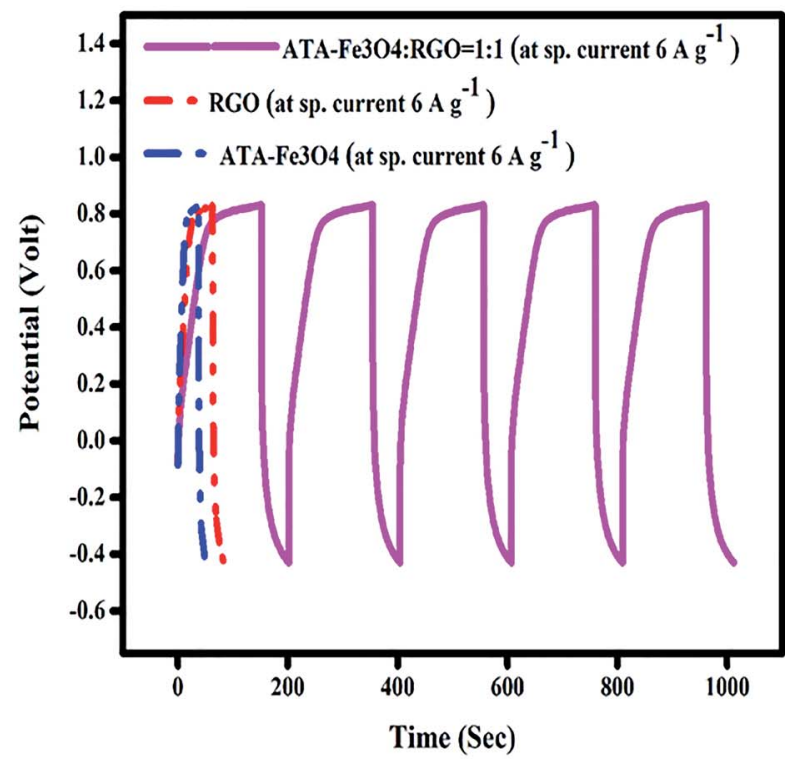

(a)

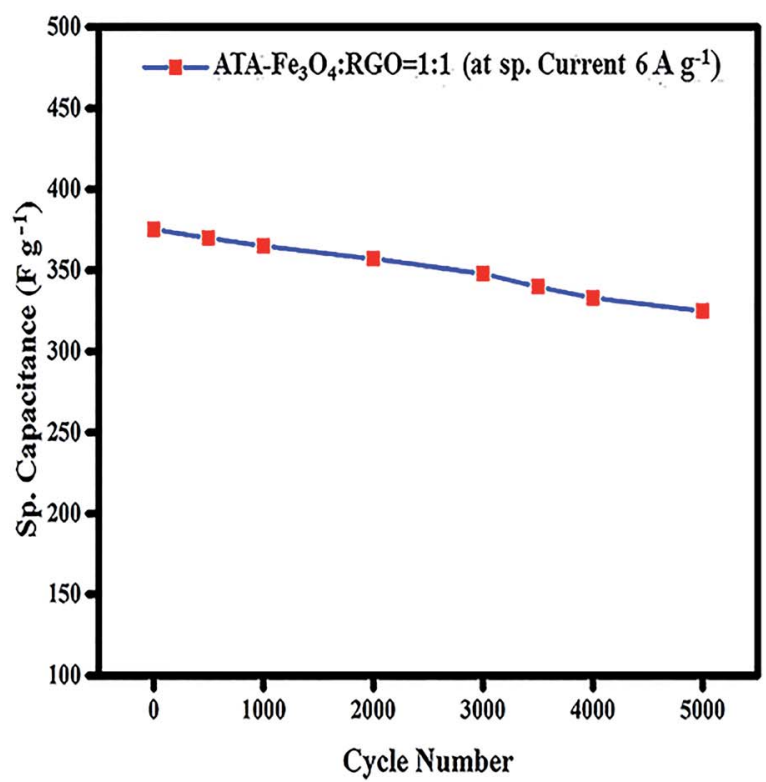

(b)

Fig. 4 (a) Galvanostatic charge/discharge curve of ATA coated $\mathrm{Fe}_{3} \mathrm{O}_{4}, \mathrm{RGO}$ and $\mathrm{ATA}-\mathrm{Fe}_{3} \mathrm{O}_{4} / \mathrm{RGO}$ nanocomposite $\left(\mathrm{ATA}-\mathrm{Fe} \mathrm{O}_{4}: \mathrm{RGO}=1: 1\right)$ in $1 \mathrm{M} \mathrm{KOH}$ solution at sp. current $6 \mathrm{~A} \mathrm{~g}^{-1}$. (b) The cycling performance of $\mathrm{ATA}-\mathrm{Fe}_{3} \mathrm{O}_{4} / \mathrm{RGO}$ nanocomposite $\left(\mathrm{ATA}-\mathrm{Fe}_{3} \mathrm{O}_{4}: \mathrm{RGO}=1: 1\right)$ in $1 \mathrm{M} \mathrm{KOH}$ solution at sp. current $6 \mathrm{~A} \mathrm{~g}^{-1}$ (up to 5000 cycle). The cycling performance of $A T A-F_{3} O_{4} / R G O$ nanocomposite $\left(A T A-F e_{3} O_{4}: R G O=1: 1\right)$ in $1 M$ $\mathrm{KOH}$ solution at sp. current $6 \mathrm{~A} \mathrm{~g}^{-1}$ (up to 5000 cycle). 
The energy density of the nanocomposite is further calculated by employing the formula:

$$
E=0.5 C_{\mathrm{s}} V^{2}
$$

where $E$ is the energy density, $C_{\mathrm{s}}$ is the obtained specific capacitance and $V$ is the potential window. In our case the energy density for $\mathrm{Fe}_{3} \mathrm{O}_{4} / \mathrm{RGO}(1: 1)$ composite (at $\left.1 \mathrm{mg} \mathrm{ml}^{-1}\right)$ is found to be $75 \mathrm{~W} \mathrm{~h} \mathrm{~kg}{ }^{-1}$ for $6 \mathrm{~A} \mathrm{~g}^{-1}$ current, which is significantly higher than previously reported values $67 \mathrm{~W} \mathrm{~h} \mathrm{~kg}^{-1}$ for 5 $\mathrm{A} \mathrm{g}^{-1} \cdot{ }^{33}$ The power density of the same sample is also calculated and is found to be $3500 \mathrm{~W} \mathrm{~kg}^{-1}$. These enhanced values are observed on account of strong interactions between the ATA$\mathrm{Fe}_{3} \mathrm{O}_{4}$ and RGO, wherein the surface coating and $\pi$-conjugation of ATA play an important part leading to an enhanced overall performance of the supercapacitor.

3.2.3. Impedance spectroscopy. Electrochemical impedance spectroscopy (EIS) is a non-destructive, easy and fast tool to extract the kinetic information of the electrode materials ${ }^{62}$ wherein the data is obtained in the form of Nyquist plot where the real part of impedance is plotted against the imaginary part of the impedance $\left(Z^{\prime}\right.$ vs. $\left.-Z^{\prime \prime}\right) .{ }^{63}$ In our experiments, an a.c perturbation voltage with a r.m.s value of $10 \mathrm{mV}$ was applied while the frequency was varied from $0.1-100 \mathrm{kHz}$. In order to compare all the different electrode materials in a coherent way, after obtaining the impedance spectra all the data plots were normalised by electrode surface area. The Nyquist plots shown in Fig. 5 clearly indicate three distinct regions. At high frequency the curves are semi-circular in nature; the bend indicates the charge transfer resistance within the electrode materials. ${ }^{64}$ In the low frequency region, a liner plot which makes an angle $45^{\circ}$ with the real axis is observed. This is known as Warburg line, and the impedance corresponds to it is the Warburg impedance ${ }^{49,65}$ which originates due to the frequency dependent ion transport/diffusion at electrode electrolyte interface. ${ }^{66}$ At very low frequencies, an almost vertical line parallel to imaginary impedance axis is observed which corresponds to ideal ion diffusion behaviour. ${ }^{67}$ Fig. 6 shows the Nyquist plots for pristine RGO, pristine ATA- $\mathrm{Fe}_{3} \mathrm{O}_{4}$ and ATA$\mathrm{Fe}_{3} \mathrm{O}_{4} / \mathrm{RGO}$ (1:1) nanocomposites. The diameter of the

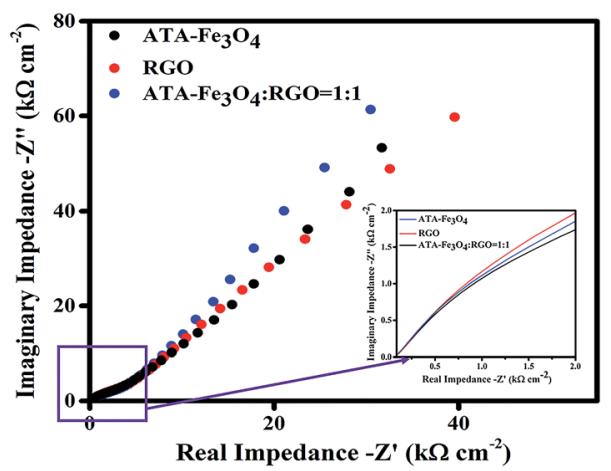

Fig. 5 Nyquist plot of experimental impedance data for ATA- $\mathrm{Fe}_{3} \mathrm{O}_{4}$, $\mathrm{RGO}$ and $\mathrm{ATA}-\mathrm{Fe}_{3} \mathrm{O}_{4} / \mathrm{RGO}$ nanocomposite $\left(\mathrm{ATA}-\mathrm{Fe}_{3} \mathrm{O}_{4}: \mathrm{RGO}=\right.$ $1: 1)$ in the frequency range of $100 \mathrm{kHz}$ to $100 \mathrm{~Hz}$. Inset shows the zoomed view at high frequencies $(>5 \mathrm{kHz})$.

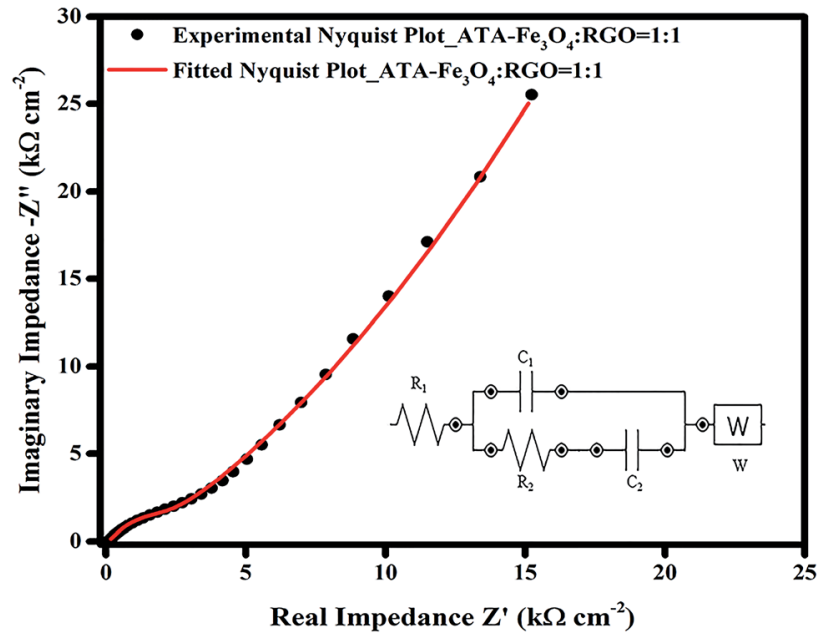

Fig. 6 Nyquist plot of experimental and fitted impedance data for ATA- $\mathrm{Fe}_{3} \mathrm{O}_{4} / \mathrm{RGO}$ nanocomposite $\left(\mathrm{ATA}-\mathrm{Fe}_{3} \mathrm{O}_{4}: \mathrm{RGO}=1: 1\right.$ ). Black dot represents the experimental data whereas the red line corresponds to the fitted data (inset shows the equivalent electrical circuit).

semicircle of the Nyquist plot provides the magnitude of the charge transfer resistance. ${ }^{68}$ The inset of Fig. 6 shows less circularity of impedance data corresponding to a smaller charge-transfer resistance, which is favourable for supercapacitor materials, thereby suggesting that the electrochemical performance is enhanced due to the synergistic effect between the ATA- $\mathrm{Fe}_{3} \mathrm{O}_{4}$ and RGO. ${ }^{69,70}$

The EIS data was further fitted using a model equivalent electrical circuit (inset of Fig. 6). The circuit corresponds to a resistance $\left(R_{1}\right)$, which includes solution resistance and contact resistance, a charge transfer resistance $\left(R_{2}\right)$ (occurring from faradic redox reactions), a double layer capacitance $\left(C_{1}\right)$ at the interface, a limit capacitance $\left(C_{2}\right)^{71}$ and a Warburg impedance $(W)$. The fitted and the experimental data are plotted in Fig. 6 and it shows a residual $\chi^{2}$ value of 0.022 confirming an excellent fitting. The values of each component of the equivalent electrical circuit model was tabulated in Table S2 (ESI $\dagger$ ). The small value of $R_{1}(\sim 12 \Omega)$ obtained from the fitting also confirms a better electrochemical performance of the supercapacitor electrode material. The change in the nature of the Nyquist plot with the increase in the cycling is also plotted (Fig. S12, ESI $†$ ), wherein the $X$-axis of $2^{\text {nd }}$ and $3^{\text {rd }}$ plots is shifted to enable clarity. The nature and the shape of all the curves remain similar, which suggests good electrochemical performance and long term electrode stability. ${ }^{33,54}$ Only the magnitude of charge transfer resistance is increased slightly ${ }^{72}$ which may obstruct ion transfer resulting in decrease in overall capacitance. The increase in $R_{2}$ values may occur, as discussed earlier, due to the agglomeration of iron oxide particles during charging. ${ }^{73}$ This is consistent with our finding from the charge-discharge analysis where $14 \%$ of capacitance loss is observed after 5000 cycles.

The long term charging discharging analysis and impedance spectroscopy reflects that there are no substantial morphological and/or structural changes in the nanocomposites. However, 
for further confirmation FTIR and SEM analysis were performed before and after the cycling.

To investigate any alteration in the functional groups, we have carried out FTIR analysis of the sample before and after cycling (Fig. S13, ESI $\dagger$ ) we can clearly infer that there is no significant change in the transmission spectra; indicative of no structural alteration. Both spectra contain the identical bands. The presence of -CONH linkage $\left(\sim 1570 \mathrm{~cm}^{-1}\right)$ after the cycling clearly suggest that ATA is still attached to the nanoparticles surface and the coating is not damaged (Fig. S13†). To spot any significant morphological change, SEM analysis was performed on the ATA- $\mathrm{Fe}_{3} \mathrm{O}_{4}: \mathrm{RGO}=1: 1$ sample before and after the charging/discharging cycling experiment. The SEM images are shown in Fig. S14 (ESI†). From the figure, it is evident that there is no substantial change in the microstructure. Apart from agglomeration in few areas the nanoparticles remain intact, which further confirms the long-term stability of the nanocomposites.

\section{Conclusions}

In summary, a novel ATA- $\mathrm{Fe}_{3} \mathrm{O}_{4} / \mathrm{RGO}$ nanocomposite was synthesized. The surface coating of $\mathrm{Fe}_{3} \mathrm{O}_{4}$ by ATA not only provides stability to nanoparticles but also endows it with faster charge transport via anchoring with the residual functional groups of the RGO. The nanocomposite showed significantly higher capacitance values than the pristine $\mathrm{Fe}_{3} \mathrm{O}_{4}$ and RGO components. At the optimized $\mathrm{Fe}_{3} \mathrm{O}_{4} / \mathrm{RGO}$ ratio $(1: 1)$, concentration $\left(1 \mathrm{mg} \mathrm{ml}^{-1}\right)$ and loading $(12 \mu \mathrm{g})$, a maximum capacitance of $576 \mathrm{~F} \mathrm{~g}^{-1}$ was achieved (at $10 \mathrm{mV} \mathrm{s}^{-1}$ ). Likewise, a high energy density of $75 \mathrm{~W} \mathrm{~h} \mathrm{~kg}^{-1}$ (at $6 \mathrm{~A} \mathrm{~g}^{-1}$ ) was also achieved at the same ratio and concentration. The ATA- $\mathrm{Fe}_{3} \mathrm{O}_{4} / \mathrm{RGO}$ system displays promising long term stability with the retention of $86 \%$ of the capacitance even after 5000 cycles. These results reveal the potential use of ATA- $\mathrm{Fe}_{3} \mathrm{O}_{4} / \mathrm{RGO}$ nanocomposite for high performance electrochemical energy storage applications.

\section{Acknowledgements}

Gourav Bhattacharya, Ravi Kant Upadhyay and Sujit Deshmukh are indebted to Shiv Nadar University for providing scholarship. The authors are also thankful to Prof. Subhasis Ghosh, School of Physical Sciences, Jawaharlal Nehru University, for his support and useful discussions.

\section{References}

1 P. Simon and Y. Gogotsi, Nat. Mater., 2008, 7, 845-854.

2 T. Y. Wei, C. H. Chen, H. C. Chien, S. Y. Lu and C. C. Hu, Adv. Mater., 2010, 22, 347-351.

3 M. F. El-Kady and R. B. Kaner, Nat. Commun., 2013, 4, 1475. 4 X. Yu, B. Lu and Z. Xu, Adv. Mater., 2014, 26, 1044-1051.

5 L. L. Zhang and X. Zhao, Chem. Soc. Rev., 2009, 38, 25202531.

6 F. Su and M. Miao, Nanotechnology, 2014, 25, 135401.

7 Q. Yang, Z. Lu, Z. Chang, W. Zhu, J. Sun, J. Liu, X. Sun and X. Duan, $R S C A d v ., 2012,2$, 1663-1668.
8 S. Senthilkumar, R. K. Selvan, N. Ponpandian and J. Melo, RSC Adv., 2012, 2, 8937-8940.

9 K. S. Ryu, K. M. Kim, N.-G. Park, Y. J. Park and S. H. Chang, J. Power Sources, 2002, 103, 305-309.

10 T. Gujar, V. Shinde, C. Lokhande, W.-Y. Kim, K.-D. Jung and O.-S. Joo, Electrochem. Commun., 2007, 9, 504-510.

11 V. Ganesh, S. Pitchumani and V. Lakshminarayanan, J. Power Sources, 2006, 158, 1523-1532.

12 W. Yu, B. Li and S. Ding, Nanotechnology, 2016, 27, 075605.

13 F. Li, J. Song, H. Yang, S. Gan, Q. Zhang, D. Han, A. Ivaska and L. Niu, Nanotechnology, 2009, 20, 455602.

14 X. Zhang, H. Zhang, C. Li, K. Wang, X. Sun and Y. Ma, RSC Adv., 2014, 4, 45862-45884.

15 J. A. Davis, R. O. James and J. O. Leckie, J. Colloid Interface Sci., 1978, 63, 480-499.

16 M. Kim, C. Lee and J. Jang, Adv. Funct. Mater., 2014, 24, 24892499.

17 C. X. Guo and C. M. Li, Energy Environ. Sci., 2011, 4, 45044507.

18 L. L. Zhang, R. Zhou and X. Zhao, J. Mater. Chem., 2010, 20, 5983-5992.

19 J. Yan, Z. Fan, T. Wei, W. Qian, M. Zhang and F. Wei, Carbon, 2010, 48, 3825-3833.

20 Y. Zhu, S. Murali, M. D. Stoller, K. Ganesh, W. Cai, P. J. Ferreira, A. Pirkle, R. M. Wallace, K. A. Cychosz and M. Thommes, Science, 2011, 332, 1537-1541.

21 X.-h. Xia, J.-p. Tu, X.-l. Wang, C.-d. Gu and X.-b. Zhao, J. Mater. Chem., 2011, 21, 671-679.

22 B. Conway and E. Gileadi, Trans. Faraday Soc., 1962, 58, 2493-2509.

23 P. J. Hall, M. Mirzaeian, S. I. Fletcher, F. B. Sillars, A. J. Rennie, G. O. Shitta-Bey, G. Wilson, A. Cruden and R. Carter, Energy Environ. Sci., 2010, 3, 1238-1251.

24 M. Zhi, C. Xiang, J. Li, M. Li and N. Wu, Nanoscale, 2013, 5, 72-88.

25 R. Ning, J. Tian, A. M. Asiri, A. H. Qusti, A. O. Al-Youbi and X. Sun, Langmuir, 2013, 29, 13146-13151.

26 Q. Chu, J. Du, W. Lu, G. Chang, Z. Xing, H. Li, C. Ge, L. Wang, Y. Luo and A. M. Asiri, ChemPlusChem, 2012, 77, 872-876.

27 S. Liu, J. Tian, L. Wang, Y. Luo and X. Sun, Catal. Sci. Technol., 2012, 2, 339-344.

28 P. M. Hallam, M. Gómez-Mingot, D. K. Kampouris and C. E. Banks, RSC Adv., 2012, 2, 6672-6679.

29 X. Du, C. Wang, M. Chen, Y. Jiao and J. Wang, J. Phys. Chem. C, 2009, 113, 2643-2646.

30 Y.-H. Kim and S.-J. Park, Curr. Appl. Phys., 2011, 11, 462-466. 31 D. Guan, Z. Gao, W. Yang, J. Wang, Y. Yuan, B. Wang, M. Zhang and L. Liu, Mater. Sci. Eng., B, 2013, 178, 736-743. 32 N. Soin, S. S. Roy, S. K. Mitra, T. Thundat and J. A. McLaughlin, J. Mater. Chem., 2012, 22, 14944-14950.

33 W. Shi, J. Zhu, D. H. Sim, Y. Y. Tay, Z. Lu, X. Zhang, Y. Sharma, M. Srinivasan, H. Zhang and H. H. Hng, J. Mater. Chem., 2011, 21, 3422-3427.

34 C. Liu, Z. Yu, D. Neff, A. Zhamu and B. Z. Jang, Nano Lett., 2010, 10, 4863-4868.

35 L. Wang, Y. Liu, T. Lai, H. Liang, Z. Li, Z. Mei, F. Zhang, A. Kuznetsovd and X. Duab, RSC Adv., 2013, 3, 13059-13084. 
36 T. Kuila, P. Khanra, N. H. Kim, S. K. Choi, H. J. Yun and J. H. Lee, Nanotechnology, 2013, 24, 365706.

37 D. Maity, G. Zoppellaro, V. Sedenkova, J. Tucek, K. Safarova, K. Polakova, K. Tomankova, C. Diwoky, R. Stollberger and L. Machala, Chem. Commun., 2012, 48, 11398-11400.

38 J. Tian, R. Ning, Q. Liu, A. M. Asiri, A. O. Al-Youbi and X. Sun, ACS Appl. Mater. Interfaces, 2014, 6, 1011-1017.

39 J. Yan, Z. Fan, W. Sun, G. Ning, T. Wei, Q. Zhang, R. Zhang, L. Zhi and F. Wei, Adv. Funct. Mater., 2012, 22, 2632-2641.

40 A. K. Das, M. Srivastav, R. K. Layek, M. E. Uddin, D. Jung, N. H. Kim and J. H. Lee, J. Mater. Chem. A, 2014, 2, 13321340.

41 M. E. Uddin, R. K. Layek, N. H. Kim, D. Hui and J. H. Lee, Composites, Part B, 2015, 80, 238-245.

42 S. Stankovich, D. A. Dikin, R. D. Piner, K. A. Kohlhaas, A. Kleinhammes, Y. Jia, Y. Wu, S. T. Nguyen and R. S. Ruoff, Carbon, 2007, 45, 1558-1565.

43 S. Perumbilavil, P. Sankar, T. P. Rose and R. Philip, Appl. Phys. Lett., 2015, 107, 051104.

44 M. Kurihara and H. Nishihara, Coord. Chem. Rev., 2002, 226, 125-135.

45 M. G. Bramucci, C. M. McCutchen, V. Nagarajan and S. M. Thomas, US Pat., No. 6187569, 13-February-2001.

46 V. W.-W. Yam, C.-C. Ko and N. Zhu, J. Am. Chem. Soc., 2004, 126, 12734-12735.

47 R. Liang, L. Shen, F. Jing, W. Wu, N. Qin, R. Lin and L. Wu, Appl. Catal., B, 2015, 162, 245-251.

48 H.-Q. Li, Y.-G. Wang, C.-X. Wang and Y.-Y. Xia, J. Power Sources, 2008, 185, 1557-1562.

49 M. D. Stoller, S. Park, Y. Zhu, J. An and R. S. Ruoff, Nano Lett., 2008, 8, 3498-3502.

50 C. Vix-Guterl, E. Frackowiak, K. Jurewicz, M. Friebe, J. Parmentier and F. Béguin, Carbon, 2005, 43, 1293-1302.

51 K. Lee, S. Deng, H. Fan, S. Mhaisalkar, H. Tan, E. Tok, K. Loh, W. Chin and C. Sow, Nanoscale, 2012, 4, 2958-2961. 52 J. Cornil, D. Beljonne, J. P. Calbert and J. L. Brédas, Adv. Mater., 2001, 13, 1053-1067.

53 G. Yu, L. Hu, N. Liu, H. Wang, M. Vosgueritchian, Y. Yang, Y. Cui and Z. Bao, Nano Lett., 2011, 11, 4438-4442.
54 B. G. Choi, M. Yang, W. H. Hong, J. W. Choi and Y. S. Huh, ACS Nano, 2012, 6, 4020-4028.

55 L. Zhang, F. Zhang, X. Yang, G. Long, Y. Wu, T. Zhang, K. Leng, Y. Huang, Y. Ma and A. Yu, Sci. Rep., 2013, 3, 1408.

56 F. He, J. Fan, D. Ma, L. Zhang, C. Leung and H. L. Chan, Carbon, 2010, 48, 3139-3144.

57 P. T. Yin, T.-H. Kim, J.-W. Choi and K.-B. Lee, Phys. Chem. Chem. Phys., 2013, 15, 12785-12799.

58 T. Liu, W. Pell and B. Conway, Electrochim. Acta, 1997, 42, 3541-3552.

59 B. Qiu, Q. Li, B. Shen, M. Xing and J. Zhang, Appl. Catal., B, 2016, 183, 216-223.

60 Z. Chen, Q. Zhang, L. Huang, R. Li, W. Li, G. Xu and H. Cheng, J. Phys. Chem. C, 2014, 118, 21244-21249.

61 L. Yin, J. Wang, F. Lin, J. Yang and Y. Nuli, Energy Environ. Sci., 2012, 5, 6966-6972.

62 J. R. Macdonald, Ann. Biomed. Eng., 1992, 20, 289-305.

63 Y. Wang, Z. Shi, Y. Huang, Y. Ma, C. Wang, M. Chen and Y. Chen, J. Phys. Chem. C, 2009, 113, 13103-13107.

64 Z. Niu, W. Zhou, J. Chen, G. Feng, H. Li, W. Ma, J. Li, H. Dong, Y. Ren and D. Zhao, Energy Environ. Sci., 2011, 4, 1440-1446.

65 Q. Cheng, J. Tang, J. Ma, H. Zhang, N. Shinya and L.-C. Qin, Carbon, 2011, 49, 2917-2925.

66 D. Zhang, X. Zhang, Y. Chen, P. Yu, C. Wang and Y. Ma, J. Power Sources, 2011, 196, 5990-5996.

67 Y.-R. Nian and H. Teng, J. Electrochem. Soc., 2002, 149, A1008-A1014.

68 C. XianáGuo and C. MingáLi, Dalton Trans., 2011, 40, 63886391.

69 J. Xu, K. Wang, S.-Z. Zu, B.-H. Han and Z. Wei, ACS Nano, 2010, 4, 5019-5026.

70 C. Arbizzani, M. Mastragostino and L. Meneghello, Electrochim. Acta, 1996, 41, 21-26.

71 A. Di Fabio, A. Giorgi, M. Mastragostino and F. Soavi, J. Electrochem. Soc., 2001, 148, A845-A850.

72 T. Qi, J. Jiang, H. Chen, H. Wan, L. Miao and L. Zhang, Electrochim. Acta, 2013, 114, 674-680.

73 C.-Y. Chen, C.-Y. Fan, M.-T. Lee and J.-K. Chang, J. Mater. Chem., 2012, 22, 7697-7700. 